\title{
LAPAROSCOPIC EVALUATION OF TUBAL FACTORS IN INFERTILE PATIENTS
}

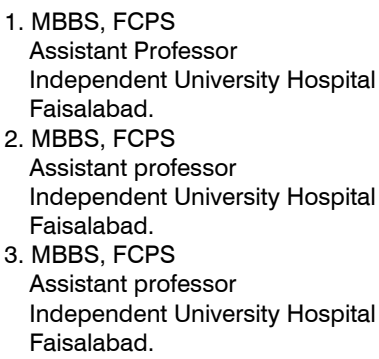

Correspondence Address:

Dr. Iram Aslam

Assistant Professor

Independent University Hospital

Faisalabad.

Article received on:

16/02/2016

Accepted for publication:

10/03/2016

Received after proof reading:

$12 / 04 / 2016$

\section{INTRODUCTION}

One of the most common and underappreciated health problems in developing countries is the high rate of infertility and childlessness. ${ }^{1}$

Unfortunately, it is a tragedy that inability to procreate is considered as a curse for the couple and it has significant impact on entire family and community also. ${ }^{2}$ There is difference in fertility rate in different regions of world and worldwide $8-10 \%$ of couples are infertile. ${ }^{3}$ Infertility is divided into primary and secondary infertility. Primary infertility is inability of a couple to conceive within one year of unprotected intercourse, while, secondary infertility refers to inability to conceive fallowing a pregnancy. Fallopian tube obstruction is one of the most frequent causes of infertility in women, approximately $20 \%$ of female infertility can be attributed to tubal causes. ${ }^{4}$ Achievement of conception is determined by extent of tubal blockade. There are different types of damage of fallopian tubes. Certain tubo peritoneal factors of infertility includes tubal scarring, unilateral or bilateral tubal blockade \& partial or complete blockade. There is strong possibility of tubal blockade in patient who has history of some tubal surgery in their past. Patency of fallopian tubes should be evaluated as early as possible in assessment of infertile couple.

There is a range of diagnostic tests which are available for assessing tubal status. The diagnostic evaluation of tubal patency in infertile women can be accomplished by performing laparoscopy, hysterosalpingogram or a saline sonogram. ${ }^{5}$

Every procedure has its own benefits or drawbacks but laparoscopy provides a panoramic view of anatomy of pelvis and magnifies view of pelvic organs. It is generally accepted that, diagnostic laparoscopy is the gold standard in diagnosing tubal pathology and other intra-abdominal causes of infertility. ${ }^{6}$ Diagnostic Laparoscopy is an endoscopic procedure and now it has become an indispensable tool while evaluating infertile patients. It is a relatively safe procedure with minimal morbidity.

Independent University Hospital is a tertiary care hospital where a huge number of patients 
present with infertility for diagnostic evaluation and management. This study aims to evaluate tubal factors related to infertility in our patients for subsequent management and future planning for improving the fertility.

\section{METHODOLOGY}

This is a retrospective study conducted in Gynecology \& Obstetrics Department of independent university Hospital Faisalabad from $1^{\text {st }}$ Jan 2013 to $31^{\text {st }}$ December 2015. 52 patients were selected for laparoscopic evaluation. Inclusion criteria was patients with no prior pelvic surgery, normal bimanual pelvic examination, normal semen parameters of partner and no ovulatory dysfunction. After obtaining thorough history \& detailed examination, patients were informed about the procedure and written informed consent was taken. Laparoscopy was performed in follicular phase of menstrual cycle, under general anesthesia. During the laparoscopy, pelvis was inspected for any adhesions or endometriotic spots. Any structural abnormalities of uterus and tubes were noted. Testing of fallopian tube patency was performed by injecting a dilute solution of methylene blue through cervix via Rubin's Canula Tubal patency assessed during laparoscopy was classified as no tubal occlusion, one or two sided tubal occlusion, proximal or distal tubal occlusion. Any complications of laparoscopy like intra operative damage to bowel or blood vessels, post-operative nausea, vomiting, pyrexia or shoulder tip pain was noted.

\section{RESULTS}

A total of 52 Patients underwent laparoscopy during the period of 01-01-2013 to 31-12-2015 at independent university hospital Faisalabad.

All the information was collected on predesigned proforma and different parameters were evaluated.

In total 52 patients 10 were in the age group of $<20$ yr, 13 were between 21-30 yr \& 19 were 31$40 \mathrm{yr}$ of age and 10 were between $36-40 \mathrm{yrs}$ of age.
Among these 52 patients 23 patients had primary infertility while 29 had presented with secondary infertility

In these 52 patients 1 had infertility of 0-1 yr, 5 had 2-4 yr while 25 patients were infertile for 5-8 yr and 21 had infertility of 9-15 yr.

When history of these patients were sought for 12 had some or other irregularity of menstrual cycle. 15 patients had history of PID, 4 patients had some tubal surgery in their past while 13 had undergone some instrumentation by dai. 3 patients had $\mathrm{H} / \mathrm{O}$ septic abortion \& 5 had underwent D\&C.

When laparoscopic findings were evaluated 12 patients had normal pelvic organs while 22 had some evidence of PID and 13 had endometriotic spots. 1 Patient was observed having some congenital anomaly of uterus (bicornuate uterus).

In 4 patients, uterine fibroids were noted \& 10 had polycystic ovaries. When tubal patency was evaluated by chromotubation 21 patients had healthy and patent tubes, in 8 patients, there were peritubal adhesions but spill seen. In 14 patients there were no spill of dye seen indicating bilateral blockade while 9 patients had dye spill on one side showing unilateral blockade of tube.

In total 52 patients who underwent laparoscopy 27 patients had primary infertility \& in these patients 9 had one or both blocked tube. While 25 patients of secondary infertility 14 had blocked tubes.

When laparoscopy associated complications were noted, there were 2 patients who had nausea \& vomiting after the procedure 3 had wound infection and none of our patients had any damage to bowel \& blood vessel. 4 patients had developed fever.

\begin{tabular}{|l|c|c|}
\hline \multicolumn{1}{|c|}{ Age(Yr) } & No of Patients & $\%$ \\
\hline$<20$ & 10 & 19 \\
\hline $21-30$ & 13 & 25 \\
\hline $31-35$ & 19 & 36 \\
\hline $36-40$ & 10 & 19 \\
\hline
\end{tabular}

Table-l. $\mathrm{n}=$ Distribution of patients by age $(\mathrm{N}=52)$ 


\begin{tabular}{|l|c|c|}
\hline Type of infertility & No of Patients & $\%$ \\
\hline Primary infertility & 23 & 44 \\
\hline Secondary infertility & 29 & 55 \\
\hline Table-II. $\mathrm{n}=$ Distribution of patients according to type \\
of infertility (N=52)
\end{tabular}

\begin{tabular}{|l|c|c|}
\hline \multicolumn{1}{|c|}{ Duration (yr) } & No of Patients & $\%$ \\
\hline $0-1 \mathrm{yr}$ & 1 & 1.9 \\
\hline $2-4$ & 5 & 9 \\
\hline $5-8$ & 25 & 48 \\
\hline $9-15$ & 29 & 55 \\
\hline \multicolumn{2}{|c|}{ Table-III. n = Distribution of patients according to } \\
duration of infertility $(\mathbf{N}=52)$
\end{tabular}

\begin{tabular}{|l|c|c|}
\hline & No of Patients & $\%$ \\
\hline Regular Menstrual Cycle & 8 & 15 \\
\hline H/O PID & 15 & 28 \\
\hline H/O Previous tubal surgery & 4 & 7.6 \\
\hline H/O Instrumentation by Dai & 13 & 25 \\
\hline H/O Septic Abortion & 3 & 5.7 \\
\hline H/O D\&C & 5 & 9.6 \\
\hline \multicolumn{2}{|c|}{ Table-IV. $n$ = Distribution of patients according to } \\
\hline \multicolumn{2}{|c|}{ Previous history (N=52) } \\
\hline
\end{tabular}

\begin{tabular}{|l|c|c|}
\hline & No of Patients & $\%$ \\
\hline Normal Pelvic organs & 12 & 23 \\
\hline PID & 22 & 42 \\
\hline Endometriosis & 13 & 25 \\
\hline Congenital anomalies of uterus & 1 & 1.9 \\
\hline Fibroids & 3 & 5.7 \\
\hline PCOD & 10 & 19 \\
\hline \multicolumn{2}{|c|}{ Table-V. $\mathbf{n}=$ Laparoscopic Findings $(\mathbf{N}=52)$} \\
\hline
\end{tabular}

\begin{tabular}{|l|c|c|}
\hline & No of Patients & $\%$ \\
\hline Bilateral Block & 14 & 26 \\
\hline Unilateral block & 9 & 17 \\
\hline Peritubal adhesions (spill seen) & 8 & 15 \\
\hline Healthy \& patent tubes & 21 & 40 \\
\hline \multicolumn{2}{|c|}{ Table-VI. $\mathbf{n}=$ Findings of Chromotubation $(\mathbf{N}=52)$} \\
\hline
\end{tabular}

\begin{tabular}{|c|c|c|}
\hline $\begin{array}{c}\text { Type of } \\
\text { infertility }\end{array}$ & $\begin{array}{c}\text { No of Patients } \\
\text { with blocked } \\
\text { tubes }\end{array}$ & $\begin{array}{c}\text { No of patients with } \\
\text { patent tubes }\end{array}$ \\
\hline $\begin{array}{c}\text { Primary } \\
\text { infertility }\end{array}$ & 9 & 39 \\
\hline $\begin{array}{c}\text { Secondary } \\
\text { infertility }\end{array}$ & 14 & 48 \\
\hline $\begin{array}{c}\text { Table-VII. } n \text { = Frequency of tubal blockade detected } \\
\text { in case of primary \& secondary infertility }\end{array}$ \\
\hline
\end{tabular}

\begin{tabular}{|l|c|c|}
\hline & No of Patients & $\%$ \\
\hline Pyrexia & 4 & 7.6 \\
\hline Nausea \& vomiting & 2 & 3.8 \\
\hline Wound infection & 3 & 5 \\
\hline Damage to bowel & - & - \\
\hline Damage to blood vessels & - & - \\
\hline \multicolumn{2}{|c|}{ Table-VIII. $\mathbf{n}=$ Complications of Laparoscopy } \\
\hline
\end{tabular}

\section{Statistical Analysis}

All data was entered and analyzed using SPSS version 16 . The variables were stratified. Quantitative variables like age and duration of infertility has been presented as mean \& standard deviation. Qualitative variables like type of infertility, previous history, laparoscopic findings of chromotubation, complication of laparoscopy were presented as frequency and percentage. A test of significance was applied. $P$ value of 0.05 or less was considered significant.

\section{DISCUSSION}

Exploration of the female genital tract is one of the essential elements of infertility assessment. Laparoscopy is considered as a gold standard method in assessment of tubal patency. 25 to $30 \%$ of infertile couples have some contribution of tuboperitoneal factors in their infertility.

In our study, we have collected data in independent university Hospital, Faisalabad, where a huge number of infertility patients visit for their diagnosis and subsequent management. Laparoscopy is a mandatory procedure for full assessment of infertile couple.

Age of female partner is a significant determinant factor in achieving conception and although, there 
is no universally accepted definition of advanced maternal age, 35yr is considered as the limit in fertility term.

In our study 10 patients were in age group of $\leq$ 20 yr, 13 were between 21-30 yr \& 19 were 31-35 year of age and 10 patients were 36 - 40 yr of age. These results were similar to study where mean age of patients was $31 \mathrm{yr}^{7}$

In our study, 23 patients had primary infertility while 29 had presented with secondary infertility. It was observed in a study where tubal pathology was detected in $64.7 \%$ of primary infertility and $68.7 \%$ of secondary infertility. ${ }^{8}$

We observed one patient with duration of infertility 0-1yr, 5 pts had 2-4 yr while 25 patients had infertility for 5-8 yr \& 21 had 9-15 yr of infertility. In a study conducted in Khulna (India) maximum duration of infertility was within 1-6 $\mathrm{yr}^{9}$

In our study 12 patients had some or other menstrual irregularity. 15 Patients has history of PID, 4 patients had some tubal surgery in their past while 13 had some instrumentation by dai, 3 patients had $\mathrm{H} / \mathrm{O}$ septic abortion \& 5 had underwent D\&C. In a study conducted in Hyderabad (Pakistan) among all who presented with secondary infertility $16.6 \%$ were asymptomatic while $27.2 \%$ had dyspareunia as commonest symptom. $16.6 \%$ had $\mathrm{H} / \mathrm{O}$ pelvic pain and $16 \%$ had history of irregular cycle and $50 \%$ of patients who presented with primary infertility had previous D\&C. while in secondary infertility $44 \%$ had previous LSCS. ${ }^{10}$

The diagnostic laparoscopy should be considered early in symptomatic patients during infertility work up. In our study, we observed a wide range of findings on laparoscopy ranging from normal pelvic anatomy, endometriosis, PID, PCOD, fibroids and congenital abnormality of uterus. Out of 52 patients 12 patients had normal pelvic organs, 22 showed evidence of PID. There were scarring and adhesion formation between pelvic structures. In our country, incidence of PID is quite high among infertile patients and it is obvious that untrained health professionals, lack of sterilization, poor education regarding safe sex, improper use of antibiotics all play role in high prevalence of PID and this in turn, is a major contributor of infertility by causing blockade of tubes. When laparoscopic findings were evaluated 13 showed evidence of endometriosis. In contrast to this, in a study conducted by Mahmood incidence of endometriosis was in $13.6 \%$ of patients in case of primary infertility \& 2.5 in case of secondary infertility. ${ }^{11}$ It is estimated that between 30 and $40 \%$ of patients with endometriosis complain of difficulty in conception. Several factors are important in causing sub fertility in patients of endometriosis. There is some anatomical distortion; there is presence of adenexal adhesions and destroyed ovarian tissue in endometriosis.

In our study one patient was observed having congenital anomaly of uterus (bicornuate uterus), In 4 patients, uterine fibroid was observed and 10 patients had PCOD.

In a study, 52\% had normal pelvic organ and incidence of congenital tubal anomalies \& hypoplasia of uterus and fallopian tube was about $3 \%$.

In another study, laparoscopy revealed normal findings in 10 out of 50 patients, $25 \%$ with primary infertility and $15.6 \%$ with secondary infertility. Abnormal findings were present in $80 \%$ patients. It was seen that the most common cause observed by laparoscopy was tubal occlusion (26\%) this was followed by polycystic ovaries (15.6\%), endometriosis (12.5\%) in case of primary infertility while peritubal and periovarian adhesions (22\%) and PID (16.7\%) were second most common causes in cases of secondary infertility. ${ }^{12}$

In a study, laparoscopy findings in infertile patients were as follow, $14.1 \%$ with adnexal cyst or adhesions. $19.8 \%$ had uterine fibroids, $18.9 \%$ had endometriosis \& $5.9 \%$ had tubal pathology either dilation or peritubal adhesions. ${ }^{13}$ In our country tubal factor is a major contributor in infertility as in our developing country, there is high incidence of PID with limited resources of patient to seek a 
health care provider and subsequent diagnosis and management is too late.

In our study out of 23 patients who presented with primary infertility 9 had blocked tubes 8 Patients with primary infertility had normal tubal patency.

In patients with secondary infertility out of 29 patient 15 had normal tubal patency while 14 (48\%) had blocked tubes, In contrast to our study; tubal obstruction was found in $73.3 \%$ of patients. ${ }^{14}$

When laparoscopic associated complication were noted, there were 2 patients who had nausea $\&$ vomiting 3 had wound infection and none of our patients had any damage to bowel \& blood vessels.

In a large finish follow up study the complication rate of diagnostic laparoscopy was 0.6 per 1000 procedure, and the most common complication were pyrexia, should tip pain, nausea \& vomiting. ${ }^{15}$

\section{CONCLUSION}

Laparoscopy is an effective diagnostic total for evaluation of pelvic pathologies especially related to fallopian tubes. Laparoscopy and chromotubation test should be performed as a first step in investigation of infertile women especially those with history of PID and pelvic surgery.

In Pakistan, most of patients seek advice from untrained health professionals. Poverty, lack of awareness, low socioeconomic profile and pressure from family all add to misery of poor infertile patients. We as trained gynecologists should strive for educating these ladies \& counselling them regarding need of evaluation of their infertility by proper methods \& laparoscopy not only help in identification of unsuspected pathology, but also help us in future decision making regarding their treatment.

Copyright (C) 10 Mar, 2016.

\section{REFERENCES}

1. Leke RJ. The prevalence of infertility and its preventive measures in sub-Saharan Africa in sekadde-Kigondu C, chikamata D, Franken D. Management of infertility in AFRO \& EMRO countries. Geneva, Switzerland: World Health organization Proceedings of a workshop 2002; 79-91.

2. Ombelet W, Cooke J, Dyer S, Serour G, Devroey P. Infertility and the provision of infertility medical services in developing countries. Hum reprod update. 2008; 14: 605-21.

3. Bushnik T, Cook JL, Yuzpe AA. Tough S, Colling J. Estimating the prevalence of infertility in Canada. Hum Reprod. 2012; 27: 738-46.

4. Adamson PC, Krupp K, Freeman AH Klausner JD, Reigngold $A L$, Madhivanan $P$, Prevalence and correlates of primary infertility among young women in Mysore, India. J Med Res.2011; 134:440-6.

5. Adesiyun AG, Ameh CA. Hysterosalpingographic tubal anomalies and HIV infection among black women with tubal infertility in Sub Saharan Africa. Gyecol Obstet invest 2008; 66:119.22.

6. Tanahatoe SJ, Hompes PG, Lambalk CB, Investigation of the infertile Couple. Should diagnostic laparoscopy be performed in the infertility work up program in patients undergoing intrauterine insemination? Hum Reprod. 2003:18-8.

7. Hu Chaunxiu, Chen Z, H Han, Xiao E, Kong X, Chen $Y$. Infertility evaluation via laparsacopy and hysteroscopy after coservative treatment for tubal pregnancy. Int J Clin Med 2014; 7:3556-61.

8. Shetty SK et al. laparoscopic evaluation of tubal factor in cases of infertility. Int $\mathrm{J}$ Reprod Contracept Obstet Gynaecol 2013; 2:410-13.

9. S Nahar, D Jahan, N Akter, B Das. Laparoscopic evaluation of tubo peritoneal causes of infertility. Bang Med J Khulna 2013; 46:16-20.

10. Aziz N. Laparoscopic evaluation of female factors in infertility. JCPSP 2010; 20:649-52.

11. Mahmood S. An Audit of diagnostic Laparoscopies for infertility J Surg Pak 2003; 8-10.

12. Maheshwari A, Hamilton M, Bhattachrya S. Effect of female age in the diagnostic categories of infertility. Hum Reprod 2008; 23:538-42.

13. Ikechebelu Jl. Experience with diagnostic Laparoscopy for gynecological indications. Niger $\mathrm{J}$ clin Pract. 2013; 16:155-8.

14. Stulberg DB. Cain LR, Dahlquist I, Lauderdale DS. Ectopic Pregnancy rates in the Medicaid prpulation. 
Am J Obstet Gynaecol, 2013; 208:274?

15. Dun EC, Nezhal CH. Tubal factor infertility. Diagnosis and management in the era of assisted reproductive technology. Obstet Gynacol Clin North Am. 2012; 39:51-66.

\title{
PREVIOUS RELATED STUDY
}

Waseem Talib, Mohammad Ikram, Maimoona Hafeez, Mohammad Saeed. INFERTILE FEMALE;LAPAROSCOPIC EVALUATION (Original) Prof Med Jour 14(04) 562-566 Oct, Nov, Dec, 2007.

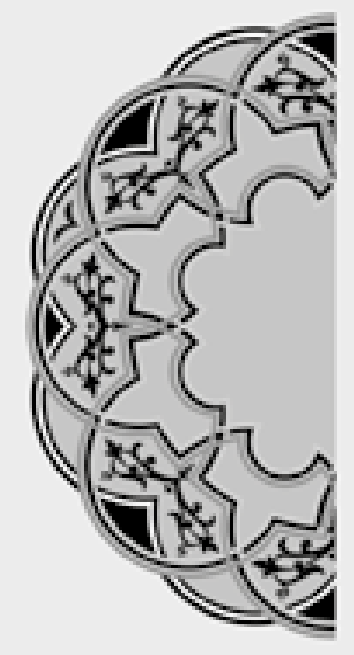

\section{"I fear not the man who has practiced 10,000 kicks once, but I fear the man who has practiced one kick 10,000 times"}

\author{
Bruce Lee
}

\begin{tabular}{|c|c|c|c|}
\hline \multicolumn{4}{|c|}{ AUTHORSHIP AND CONTRIBUTION DECLARATION } \\
\hline Sr. \# & Author-s Full Name & Contribution to the paper & Author $=$ s Signature \\
\hline 1 & $\begin{array}{l}\text { Dr. Iram Aslam } \\
\text { Dr. Tasneem Azhar }\end{array}$ & $\begin{array}{l}\text { Main Author } \\
\text { Co Author }\end{array}$ & $y+x=$ \\
\hline 3 & Dr. Nadia Awais & Co Author & Whizastif \\
\hline
\end{tabular}

